\title{
Erratum to: Outcomes of concomitant ventral hernia repair performed during bariatric surgery
}

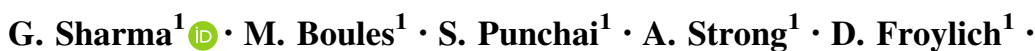
N. H. Zubaidah ${ }^{1}$ - C. O'Rourke ${ }^{1}$ - S. A. Brethauer ${ }^{1} \cdot$ J. Rodriguez $^{1}$. K. El-Hayek ${ }^{1}$ - M. Kroh ${ }^{1}$

Published online: 12 September 2016

(c) Springer Science+Business Media New York 2016

\section{Erratum to: Surg Endosc}

DOI 10.1007/s00464-016-5143-z

The correct spelling of the fifth author's name is Dvir Froylich.

The online version of the original article can be found under doi: $10.1007 / \mathrm{s} 00464-016-5143-\mathrm{z}$.

G. Sharma sharmag@ccf.org

1 Digestive Disease Institute, Cleveland Clinic, 9500 Euclid Ave/A100, Cleveland, OH 44195, USA 